\title{
Motivations for sustainability engagement among small tourism enterprises
}

\author{
B. Tomasella \\ Sustainable Tourism Ireland, Ireland
}

\begin{abstract}
This qualitative research was carried out in Ireland during the summer of 2010. It investigated how to support small and medium tourism enterprises (STEs) in engaging in more sustainability practices. The research qualitatively explored the uptake of sustainability practices among STEs in Ireland, where the research sample and case studies are located; moreover, it aims to explore the effectiveness of sustainability learning tools on the uptake of sustainability practices among STEs, especially in the marketing area. It emerged that internal factors to the enterprise - like goal orientation, locus of control and self-efficacy - are more linked to higher level of sustainability engagement, than external factors to the company; also management skills and sustainability learning are mediating factors influencing higher levels of sustainability engagement. The findings confirmed the importance of networking and ongoing education, as well as highlighting the lack of actions so far taken by governments and agencies to stimulate small companies to incorporate sustainability into their operational practices. While it is evident that the tourism sector is primarily made up of small actors, the actions undertaken to support the growth of sustainable tourism have been limited to promoting information only related to the environmental area and highlighting the cost-saving factor. Sustainability learning for small and medium enterprises (SMEs), especially forms of learning which guarantee reflection and action through learning by doing, are very effective forms of learning; it's also easier to maintain a higher motivation to learning in the long term through implementing network learning, as well as offering some form of mentoring. The overall research uncovered the necessity for policy makers and planners to focus on activities and policies which promote the growth of human factors, the most crucial in motivating companies to further engage in sustainability; it is when managers personally engage in sustainability as a valuable tool, that they will engage in
\end{abstract}


ongoing sustainability learning: when that happens, the company will engage in sustainability practises in the long term.

Keywords: small tourism businesses, sustainability practises, sustainability learning, tourism networking groups, entrepreneurship, learning by doing, selfefficacy.

\section{Background}

The starting point of this research is the awareness that the fragmented tourism industry, composed for the majority by small and medium tourism enterprises (STEs), benefits hugely from their local distinctiveness and boost they bring to local economies. Unfortunately, the negative impacts produced by small tourism enterprises on the environment, ecology and social structure of the regions in which they operate, often neglected at individual level, are relevant at aggregated level. Hence it is crucial, for the advancement of the responsible tourism agenda, to support STEs in engaging in more sustainability practices in order to alleviate their negative impacts.

While governments and other institutions encourage the economic advantages small and medium enterprises (SMEs) bring to local economic development, the actions so far taken to stimulate SMEs to incorporate sustainability into their operational practices have been limited only to promoting information and the cost-savings in the environmental area. The objective of this research was consequently to explore what best influences and motivates STEs to engage in more sustainability practices, in order to inform recommendations for agencies and governments on effective strategies and programs to encourage more tourism companies to implement sustainability practises.

\section{Literature review}

\subsection{Sustainability behaviour among tourism SME: influences and barriers to the tourism entrepreneur's decision making process}

The focus of this research is on small tourism businesses and their engagement with sustainability: the particular interest stems from the fact that usually these companies are left out of the attention from government policies, as they are considered too small. Similarly, SMEs often do not perceive the necessity to uptake sustainability, as they believe that their impacts are negligible [1]. But small tourism companies, employing fewer than 10 people, amount to more than $90 \%$ of all tourism firms, forming the backbone of the tourism industry [2]. This means that also their overall environmental impact is not negligible: it is estimated that SMEs in the UK are responsible for as much as $60 \%$ of industry's carbon dioxide emissions, $60 \%$ of commercial waste and 8 out of 10 pollution accidents [3].

Many studies have been conducted over the years trying to fully understand the attitudes and behaviours of companies with regards to engaging in environmental and sustainability practices. Much of these researches have seemingly failed to 
grasp the actual behaviours of SMEs, or at least found discordance between what companies say and what they actually do in terms of environmental commitment [5]. Nevertheless, many other studies also highlight the mentioned 'value-action' gap, whereby the extensive barriers experienced by entrepreneurs cause their generally positive environmental attitudes to rarely translate into concrete actions [6].

Any study on entrepreneurial action recognises that there are a myriad of factors influencing the decisional process, not only attitudes and behaviours, but also environmental factors, situational factors, opportunities, etc. [7-9]. For example, the availability of recycling facilities (environmental factor) is recognised as an important incentive for companies to recycling, even among companies without strong environmental attitudes [10]. Often cited barriers to sustainability are financial constraints [12]. Positive influences are actions of others, as well as cost savings, but not as influential as found for bigger sized companies.

Many studies found links between the following personal values/attitudes and environmentally sustainable business practices $[13,14]$ : a) Locus of control, which is referred to as the awareness about environmental imperatives and individual actions required; b) Self-efficacy: it is the belief in one's ability to employ the necessary amount of resources, skills and competencies to obtain a certain level of achievement on a given activity (Bandura [15]); c) Goal orientation: it describes the type of willingness that individuals have about learning and unfamiliar activities, like sustainability engagement. The theory distinguishes between those that are mastery goal oriented, i.e. have a learning orientation, being more at ease with learning new skills because they are motivated by new learning; versus those that are performance goal oriented, i.e. are motivated by gaining favourable judgment to their performance, consequently more inclined towards activities they are familiar with, while less inclined towards new learning (Button et al. [16]).

\subsection{Sustainability learning}

Raising awareness about sustainability can be best achieved through training and education "to engender within the tourism industry a wholehearted acceptance of the principles and requirements of a sustainable tourism approach" (Woodland and Acott [17, p. 731]). In fact, as sustainability is an ongoing process of development and innovation, learning becomes a key factor in achieving the ongoing attitude of continuous innovation required to embrace sustainability [18]. As sustainability is closer to being a process rather than an outcome, it is argued that openness to sustainability learning can be best found in those entrepreneurs and companies which prefer to approach tasks through learning and mastering (hence focused on the process), rather than performing (focus on the outcome) [19]. In the context of SMEs, as they mainly depend on the owner manager, it is obvious that the sustainability learning is very much related to also performing the actions of entrepreneurship related to pursuing main business opportunities [20], i.e. experiential learning is very important. This is confirmed as it seems most common for small firms to go without formalised forms of learning [21]. Learning by doing (i.e. learning from experience) is deemed very important as it's the ability 
to reflect on past strategy and mistakes, in order to develop new skills and actions; Ballard [22] points directly at experiential learning as a way to develop more selfefficacy. He affirms that "developing agency is a key process in change for sustainable development: action and reflection are perhaps crucial in developing it (...). Action and reflection are processes that are central to learning”.

\section{Methodology}

It was decided to focus the attention on STEs part of the Greenbox, a tourism area advertised as "Ireland's first integrated ecotourism destination"; the choice of focusing on a specific group of companies was done in order to guarantee a similar level of input and commercial environment (a variable in motivational studies that needs to be kept controlled to guarantee reliability of the data), as well as providing a uniquely interesting case study (second part of the research), around the many learning opportunities that these companies were exposed to over the years.

The first half of the qualitative research comprised semi-structured interviews, because they can allow flexibility in exploring the motivations behind certain actions (O'Leary [23]). The final response rate was approximately $37 \%$ for a total of 10 interviews, involving approximately 13 people, as in 3 cases it is a couple running the enterprise. There was a balance spread among various type of companies (accommodation, activity providers). The questionnaire involved questions on the sustainability practises undertaken, as well barriers and incentives, both to further practises and to sustainability learning; some questions were also introduced to measure goal orientation and self-efficacy. All the results are summarised in Table 1.

The initial qualitative analysis, which included observations about the learning experience of being part of the Greenbox network, gave the researcher the idea of focusing on a specific learning event, in order to evaluate its effectiveness on the sustainability learning of small tourism companies. Because of limitations in timeframe and resources involved in this research, it was decided to focus primarily on evaluating the effects of one specific learning experience. A case study approach has consequently been chosen, as it allowed for different data collection methods to be employed [24].

The choice of case-studies has been offered by a sub-sample of the companies involved in the first part of the research. The learning intervention, which focused on communication marketing for sustainability, was geared towards coaching the company to produce their own sustainability marketing/communication plan, utilising the learning contained in a sustainability marketing manual, during the specified timeframe of two months. In evaluating the learning experience, it was important to distinguish between types of learning that took place (knowledge based versus reflective or transformative), as well gauging the level of experiential learning. A taxonomy often utilised for sustainability learning, is the one referring to the domain of "head, hands and hearts" [25]:

- The head element corresponds to rationality, as it augments the actual knowledge which directly affects the engagement of the individual in sustainability; 
- Hands, which is the most practical side of a training, is fundamental as it gives practical applicability to a topic and increases skills and abilities of students; this area corresponds to the learning by doing;

- Heart corresponds to transformative learning, as the learning objectives are related to creating transformative change in the individual, especially in his values related to sustainability.

Table 1: Sustainability actions undertaken by interviewed entrepreneurs.

\begin{tabular}{|c|c|c|c|c|}
\hline $\begin{array}{l}\text { Type of activity/ } \\
\text { gender }(\mathrm{m} / \mathrm{f})\end{array}$ & Education & $\begin{array}{c}\text { Other work } \\
\text { experiences, } \\
\text { management skills }\end{array}$ & $\begin{array}{l}\text { Sustainability actions } \\
\text { implemented }\end{array}$ & $\begin{array}{c}\text { Goal } \\
\text { orientation }\end{array}$ \\
\hline $\begin{array}{l}\text { (1) Activity centre } \\
\text { (f). }\end{array}$ & $3^{\text {rd }}$ level & $\begin{array}{l}\text { Marketing manager; } \\
\text { good management } \\
\text { skills }\end{array}$ & $\begin{array}{l}\text { Energy, water, waste; organic } \\
\text { food and cleaning products; } \\
\text { procurement policy; proactive } \\
\text { protection destination; social } \\
\text { agenda; excellent marketing }\end{array}$ & MGA \\
\hline (2) $B \& B(f, m)$ & $3^{\text {rd }}$ level & $\begin{array}{l}\text { Housewife, engineer; } \\
\text { no management skills }\end{array}$ & $\begin{array}{c}\text { Energy, water, waste; organic } \\
\text { food and cleaning products; no } \\
\text { marketing }\end{array}$ & PGA \\
\hline $\begin{array}{l}\text { (3) Activity } \\
\text { centre/self- } \\
\text { catering (f) }\end{array}$ & $2^{\text {nd }}$ level & $\begin{array}{l}\text { Yoga practitioner; } \\
\text { limited management } \\
\text { skills }\end{array}$ & $\begin{array}{c}\text { Energy, water, waste; organic } \\
\text { food and cleaning products; } \\
\text { limited marketing }\end{array}$ & PGA \\
\hline $\begin{array}{l}\text { (4) Self-catering } \\
\text { (m) }\end{array}$ & $2^{\text {nd }}$ level & $\begin{array}{l}\text { Farmer; limited } \\
\text { management skills }\end{array}$ & $\begin{array}{l}\text { Energy, water, waste; organic } \\
\text { food and cleaning products; } \\
\text { proactive protection } \\
\text { destination; limited marketing }\end{array}$ & MGA \\
\hline (5) $\mathrm{B} \& \mathrm{~B}(\mathrm{~m}, \mathrm{f})$ & $3^{\text {rd }}$ level & $\begin{array}{c}\text { Civil servant, } \\
\text { housewife; no } \\
\text { management skills }\end{array}$ & $\begin{array}{l}\text { Energy, water, waste; no } \\
\text { marketing }\end{array}$ & PGA \\
\hline $\begin{array}{l}\text { (6) Camping site } \\
(\mathrm{m}, \mathrm{f})\end{array}$ & $3^{\text {rd }}$ level & $\begin{array}{l}\text { Public sector, } \\
\text { midwife; no } \\
\text { management skills }\end{array}$ & $\begin{array}{l}\text { Energy, water, waste; no } \\
\text { marketing }\end{array}$ & PGA \\
\hline $\begin{array}{l}\text { (7) Mansion } \\
\text { house }(\mathrm{m})\end{array}$ & $2^{\text {nd }}$ level & $\begin{array}{c}\text { Business and } \\
\text { managerial; good } \\
\text { management skills }\end{array}$ & $\begin{array}{c}\text { Energy, water, waste; cleaning } \\
\text { products; (limited) protection } \\
\text { of destination; limited } \\
\text { marketing }\end{array}$ & PGA \\
\hline $\begin{array}{l}\text { (8) Mansion } \\
\text { house }(\mathrm{m})\end{array}$ & $2^{\text {nd }}$ level & $\begin{array}{l}\text { Family business; good } \\
\text { management skills }\end{array}$ & $\begin{array}{l}\text { Energy, water, waste; cleaning } \\
\text { products; limited protection } \\
\text { destination; limited marketing }\end{array}$ & PGA \\
\hline $\begin{array}{l}\text { (9) Self-catering } \\
\text { (f) }\end{array}$ & $2^{\text {nd }}$ level & $\begin{array}{l}\text { Food industry; good } \\
\text { management skills }\end{array}$ & $\begin{array}{l}\text { Energy, water, waste; organic } \\
\text { food and cleaning products; } \\
\text { proactive protection } \\
\text { destination; good marketing; } \\
\text { social agenda }\end{array}$ & $\mathrm{PGA}=\mathrm{MGA}$ \\
\hline $\begin{array}{l}\text { (10) Self-catering } \\
(\mathrm{m})\end{array}$ & $3^{\text {rd }}$ level & $\begin{array}{l}\text { Building services; } \\
\text { limited management } \\
\text { skills }\end{array}$ & $\begin{array}{l}\text { Energy, water, waste; organic } \\
\text { food and cleaning products; } \\
\text { proactive protection } \\
\text { destination; limited marketing }\end{array}$ & MGA \\
\hline $\begin{array}{l}\text { (11) Activity } \\
\text { centre/self- } \\
\text { catering (f) }\end{array}$ & $2^{\text {nd }}$ level & $\begin{array}{l}\text { Alternative therapies; } \\
\text { good management } \\
\text { skills }\end{array}$ & $\begin{array}{c}\text { Energy, water, waste; } \\
\text { procurement policy; proactive } \\
\text { protection destination; good } \\
\text { marketing }\end{array}$ & SE, MGA \\
\hline
\end{tabular}

MGA=Mastery Goal Orientation; PGA=Performance Goal Orientation. 


\section{Research findings}

A number of conclusions from previous SMEs studies in other industries are confirmed. Overall, external factors tend to have a lower influence on sustainability engagement, compared to human (internal) factors. It is confirmed that human/internal factors have a comparatively higher importance than external ones in determining the engagement in sustainability of STEs [7, 8, 19]. Among the human factors, it is locus of control, self-efficacy and goal orientation, which seem to affect more the levels of company engagement in sustainability, especially through the mediating factor of sustainability learning.

Two clusters were in fact identified among the respondents (G1 is cluster of less active, G2 cluster of most active companies): G2 are companies with stronger level of mastery goal orientation compared to performance goal orientation (openness to transformative learning), with deeper understanding of the business case for sustainability (i.e. commercial factors become a motivator, with management knowledge and skills as precursors), who showed to be implementing more sustainability actions.

Dewhurst's assumption that those entrepreneurs more committed to the environment are less financially oriented is challenged (Dewhurst et al.), as well as the belief that cost-savings are a maximiser of engagement [26]. It seems instead that entrepreneurs more willing to keep improving environmentally, were also those with more commercial expectations from these, but not necessarily in the area of cost-savings [19]: in fact those companies that mentioned eco-savings among the highest motivating factors were less active in introducing a wide range of sustainability actions, especially in areas not strictly related to environmental protection; instead, commercial factors, like improving credentials and management standards, have been mentioned more often by the more proactive companies in G2; this seemed to be because the business case for sustainability is very much utilized by governments to motivate SMEs to sustainability $[3,27]$. Locus of control (awareness) was high in both clusters.

When it comes to barriers to sustainability engagement, entrepreneurs mainly mentioned financial ones, but also lack of knowledge affects the wider commitment to the overall agenda of sustainability.

The overall sustainability learning experience of the companies involved in the case study analysis was characterized by the following elements:

- Motivating factors: Good level of knowledge in the topic area (marketing, as well as management skills), self-efficacy and mastery goal orientation; where a company showed limited self-efficacy around an area, the necessary reflective process, which is crucial for allowing transformative learning, didn't take place. Another trigger to learning, it was the recognition of the marketing potential for the future [26], but this ascribes back to the knowledge and understanding on the topic.

- Learning by doing: Learning from experience is deemed very important, as it helps removing the main barrier to sustainability learning for SMEs which is lack of time and resources. In fact all companies mentioned the practical aspects of the learning experience as being critically helpful, particularly the 
one-to-one mentoring sessions which facilitated the reflective process which is crucial in the learning by doing. All these points are related to hands or practical learning: this is the crucial part of the learning, as learning by doing increases self-efficacy and indirectly locus of control.

- Network learning: Network learning is crucial in maintaining the motivations to learning high in the long term; network centered learning seems relevant especially for the tourism sector, which is a very fragmented sector, also affected by lack of formalised training on the job; all the companies in G2 joined the new Greenbox network, mentioning in various cases how being part of a community of learning facilitated the exchange of information, as well as keeping the level of interest in a topic high; it should be noted that sharing the benefits of their learning experiences with the other companies in the network, is crucial, as networking reinforces the reflective process of learning by doing [21]. Networking helps maintaining motivation for learning in the long term, proving to be crucial especially for learning in the area of sustainability, which is a process rather than a performance $[26,28]$.

\section{Recommendations and conclusions}

The results are summarized in Figure 2, which is a simplified adaptation of a model of pro-environmental behaviour from Kollmuss and Agyeman [8], expressing at graphical level the relative influence of different motivations and barriers to sustainability engagement for STEs, additionally highlighting the role of sustainability learning as an important mediating factor.

While a qualitative study doesn't clarify the exact size of these motivations and their effect on the engagement, the model gives a hypothesis on their relative prevalence as gathered in the findings, i.e. whether they directly or indirectly affect sustainability engagement, and their interrelation with the mediating factor sustainability learning. Sustainability learning is a special element which should be counted as an external factor (as it is an exogenous element often provided by external actors, so it could fall in a special category of institutional factors, like in Kollmuss et al. [8], but at the same time it influences the very human factors that are directly related with sustainability engagement.

Based on the research reported among the Greenbox companies, a number of recommendations for policy could be made in the area of strategies and programs aimed at encouraging sustainability engagement among STEs, especially those containing sustainability learning elements.

1. Traditional measures of motivating SMEs towards further sustainability engagement (for example environmental standards or legislation), employed by governments, local authorities or NGOs, have not been very effective: these programs, based principally on assuming that more knowledge alone will produce more sustainability engagement, have failed because knowledge and awareness, though important, do not cause change on their own. It is necessary to tackle the internal motivations that sustain this engagement.

2. Agencies should primarily provide learning by doing/mentoring opportunities to companies: in fact situations in which individuals can reflect on their own 
behaviour and build confidence (self-efficacy) around sustainability, as well as desire to learn, are more likely to help empowering owner managers to create the learning organization, which fosters growth of sustainability in the long term.

3. Where one-to-one mentoring is not applicable because of its high costs, webbased/telephone mentoring could be beneficial to facilitate learning by doing, as it was demonstrated through the successful case studies participating to the learning experience. Alternatively, any interactive sort of training or learning material can help to facilitate reflective thinking, which is crucial for both learning by doing and transformative learning.

4. Especially for the tourism sector, and even more for the area of sustainability, learning in networks is an extremely good method of delivering learning, as it can be very cost effective and it maintains higher the motivation to learn in the long term; moreover, it can support the marketing success of tourism networks, through increasing the awareness about the business case for sustainability.

5. Another interesting point raised is the importance of involving not only local tourism agencies in the sustainability learning processes of SMEs, but also all public agencies supporting SMEs; this is because sustainability is a long-term process and approach, which should be imbued in all aspects of the company's management and development; a concerted effort to make this happen could be the easiest way forward to progress the agenda for sustainability.

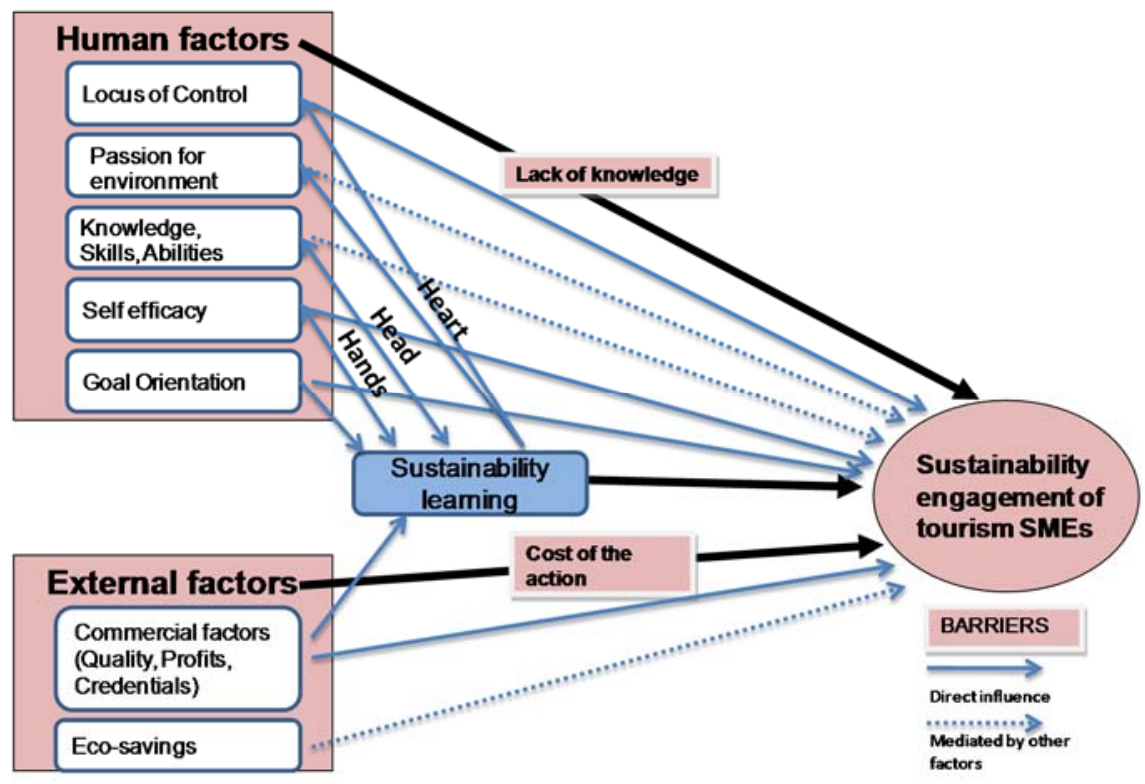

Figure 1: Adjusted model of motivation to sustainability engagement. Source: Barbara Tomasella (2011). 


\section{References}

[1] Hillary R. (2000), Small and medium sized enterprises and the environment: Business Imperatives, Sheffield: Greenleaf Publishing Limited.

[2] European Commission (2009), Study on the competitiveness of the EU tourism industry, Directorate-General Enterprise \& Industry of the European Commission [Accessed 30/05/10].

[3] Revell A. and Blackburn R. (2007), The Business Case for Sustainability? An Examination of Small Firms in the UK's Construction and Restaurant Sectors, Business Strategy and the Environment, 16: 404-420.

[4] Forsyth T. (1995), Business attitudes to sustainable tourism: Self-regulation in the UK outgoing tourism industry, Journal of Sustainable Tourism 3(6): 210-230.

[5] Thomas R. (2000), Small firms in the tourism industry: Some conceptual issues, International Journal of Tourism Research 2(5): 345-353.

[6] Maiteny P. T. (2002), Mind in the gap: Summary of research exploring 'inner' influences on pro-sustainability learning and behaviour, Environmental Education Research, 8(3): 299-306.

[7] Shane S. et al. (2003), Entrepreneurial Motivation, Human Resource Management Review, 13: 257-279.

[8] Kollmuss A. and Agyeman J. (2002), Mind the gap: Why do people act environmentally and what are the barriers to pro-environmental behaviours, Environmental Education Research, 8(3): 239-260.

[9] Halme M. and Fadeeva Z. (2000), Small and Medium-Sized Tourism Enterprises in Sustainable Development Networks - Value-Added? Greener Management International, 30: 97-113.

[10] Dewhurst H. and Thomas R. (2003), Encouraging Sustainable Business Practices in a Non-regulatory Environment: A Case Study of Small Tourism Firms in a UK national park. Journal of Sustainable Tourism.

[11] Font X. (2006), Operationalising sustainability: standard setting and certification in tourism. Ph.D. Thesis, Leeds, Metropolitan University.

[12] Vernon J., Essex S., Pinder D. and Curry K. (2003), The 'Greening' of tourism micro businesses: Outcomes of focus groups investigations in South-East Cornwall, Business Strategy and the Environment 12(1): $46-69$.

[13] Carlsen J., Getz D. and Ali-Knight J. (2001), The environmental attitudes and practices of family businesses in the rural tourism and hospitality sectors, Journal of Sustainable Tourism 9(4): 281-297.

[14] Vernon J., Essex S., Pinder D. and Curry K. (2005), Collaborative policymaking: local sustainable projects, Annals of Tourism Research, 32(2): 325-345.

[15] Bandura A. (1982), Self-efficacy mechanism in human agency, American Psychologist, 37: 122-147.

[16] Button S.B., Mathieu J.E. and Zajac D.M. (1996), Goal orientation in organizational research: A conceptual and empirical foundation, Organizational Behavior \& Human Decision Processes, 67: 26-48. 
[17] Woodland M. and Acott T.G. (2007), Sustainability and Local Tourism Branding in England's South Downs, Journal of Sustainable Tourism, 15(6): 715-734.

[18] Senge, P. (1990), The Fifth Discipline: The Art and Practice of the Learning Organization, New York: Doubleday.

[19] Sampaio A., Thomas R., Font X. (2012), Why are some engaged and not others? Explaining environmental engagement among small firms in tourism, Journal of Tourism Research, 14(3): 235-249.

[20] Lans T., Biemans H., Verstegen J. and Mulder M. (2008), The Influence of the Work Environment on Entrepreneurial Learning of Small-business Owners, Management Learning; 39(5): 597-613.

[21] Matlay H. (1999), Organisational learning in small learning organisations: an empirical overview, Education \& Training, 42(4/5): 202-210.

[22] Ballard D. (2005), Using learning processes to promote change for sustainable development, Action Research, 3(2): 135-156.

[23] O'Leary Z. (2005), Researching Real-World Problems, London: Sage.

[24] Yin R. K. (2003), Case study research: design and methods (3rd ed.), London: Sage.

[25] Sipos Y., Battisti B. and Grimm K. (2008), Achieving transformative sustainability learning: engaging head, hands and heart, Journal of Sustainability in Higher Education, 9(1): 68-86.

[26] Halme M. (2001), Learning for sustainable development in tourism networks, Business Strategy and the Environment 10(2): 100-114.

[27] Revell A., Stokes D. and Chen H. (2010), Small businesses and the environment, turning over a new leaf? Business Strategy and the Environment, 19: 273-288.

[28] Morrison A. and Texeira R. (2004), Small business performance: a tourism sector focus, Journal of Small Business and Enterprise Development, 11(2): $166-173$ 